\title{
Políticas de Escola e Currículo: algumas notas de análise construídas pelo/no contexto escolar ${ }^{1}$ \\ Fabiany de Cássia Tavares Silva \\ Geovana Mendonça Lunardi Mendes ${ }^{3}$
}

\section{RESUMO}

Políticas de Escola e Currículo: algumas notas de análise construídas pelo/no contexto escolar. Este texto apresenta resultados de pesquisas que vêm sendo desenvolvidas no Grupo de Estudos e Pesquisas Observatório de Cultura Escolar (OCE), o qual investiga o currículo como um instrumento de codificação e comunicação dos sentidos do processo de escolarização, sustentando escolhas culturais pela via da coesão e da diferenciação e suas implicações no universo escolar. Tais resultados estão sendo desenhados na hipótese de que a escola é desconsiderada como uma instituição capaz de produzir cultura e de estabelecer uma interlocução dessa cultura com as mudanças sócio-econômicas e políticas mais amplas, muito embora seja considerada palco de realização do currículo. Enquanto palco de realização, a escola desempenha um papel fundamental na distribuição de distintos tipos de conhecimento e disposições aos diferentes extratos sociais, afirmando o cunho político-ideológico do ato educativo. Em conclusão, apresentamos que as políticas de escola e de currículo adentraram o espaço escolar em finais do século XX e início do XXI, com uma força que provoca alteração na cultura escolar. Essas alterações podem ser frutos de uma mudança de discursos pedagógicos ideologizantes ou da capacidade de solicitar outras práticas, ao mesmo tempo em que possibilitam seguir fazendo o mesmo.

Palavras-chave: currículo; escola; políticas educacionais.

\section{ABSTRACT}

School and Curriculum Policies: analysis notes built by and in the school context. This text presents the results of researches that have been developed by the School Culture Observatory Research and Study Group, which investigates curriculum as a tool for coding and reporting the schooling process and sustaining cultural choices through cohesion and differentiation and its implications in the school context. The results are based on the hypothesis that school is not considered an institution capable of producing culture and establishing a dialogue between culture and socioeconomic changes, although it is considered the place in which the completion of the curriculum occurs. Due to this, schools perform an essential role in the distribution of

1 Pesquisa financiada com recursos do CNPq.

2 Professora Adjunta do Programa de Pós-Graduação em Educação da Universidade Federal do Mato Grosso do Sul.

E-mail: fabiany@uol.com.br

3 Professora Adjunta do Programa de Pós-Graduação em Educação da Universidade do Estado de Santa Catarina.

E-mail: geolunardi@gmail.com 
different types of knowledge and dispositions to different social strata, affirming the politicalideological nature of the educational act. In conclusion, we affirm that school policies and curriculum rose in the school context in the late 20th century and early 21 st century causing changes in the school culture. These changes may be the product of a change in pedagogical speech or the ability of requesting other practices, while enabling them doing the same.

Key words: curriculum; school; educational policies.

\section{NOTAS INTRODUTÓRIAS}

Este texto apresenta alguns resultados de pesquisas que vêm sendo desenvolvidas ao abrigo do Grupo de Estudos e Pesquisas Observatório de Cultura Escolar (OCE), o qual investiga o currículo como um instrumento de codificação e comunicação dos sentidos do processo de escolarização, sustentando escolhas culturais pela via da coesão e da diferenciação e suas implicações no universo escolar.

Diante disso, partimos da hipótese de que a escola é desconsiderada como uma instituição capaz de produzir cultura e de estabelecer uma interlocução dessa cultura com as mudanças sócio-econômicas e políticas mais amplas, muito embora seja considerada palco de realização do currículo. Enquanto palco de realização, a escola desempenha um papel fundamental na distribuição de distintos tipos de conhecimento e disposições aos diferentes extratos sociais, afirmando o cunho político-ideológico do ato educativo.

As pesquisas do OCE têm possibilitado investigar essa hipótese e escolhemos, neste texto, apresentar as contribuições relativas a esta questão, discutindo, num primeiro momento, o próprio conceito de escola e sua cultura e, num segundo, as políticas de currículo que a elegem como foco.

\section{A escola e as políticas de currículo: observatório da cultura escolar}

A escola torna-se um objeto de estudo cada vez mais frequente nas pesquisas desenvolvidas no país, contando com os mais diferentes enfoques de análise. Da História à Sociologia, da política educacional à prática pedagógica, cada uma dessas abordagens tem servido para colocar a escola no centro das suas preocupações investigativas. 
Além disso, nos últimos anos, a produção sobre o tema escola tem ganhado destaque na sociedade em geral. Esse aparente destaque social para a escola, presente na mídia, no cinema e nas produções literárias, coaduna com um "encharcamento" de produções também no campo científico. Muito se tem produzido, investigado e teorizado sobre a escola na área da Educação.

Tantos estudos geraram a imprecisão do termo. A palavra "escola" tornou-se uma categoria genérica e universal. A tradição da Escola Moderna, com todas as suas características, tornou-se uma expressão atemporal. Parece que, independentemente do contexto, as escolas são sempre as mesmas, por isso a imposição do uso da palavra no singular e a representação partilhada no senso comum e presente no "inconsciente coletivo".

Neste contexto, outro aspecto também amplamente partilhado é a ideia de "crise da escola". Veiga-Neto (2008), num belo insight sobre a proclamada crise da escola, se utiliza dos estudos de Giddens para destacar que a escola é um “não-lugar”, um lugar de passagem, ou um entre-lugar. É um lugar de trânsito, em que diferentes práticas unem-se e confluem.

Talvez por isso essa permanente sensação de crise. Mesmo pensando modernamente, entendemos que em muitos estudos a escola tem assumido esse espaço de não-lugar. Ou seja, ao não assumirmos que ela tem características próprias e sui generis para realizar suas práticas, roubamos sua especificidade.

Hodiernamente, tal situação tem-se intensificado pela fragilização do trabalho escolar com o conhecimento (SAMPAIO, 1998; LUNARDI-MENDES, 2005). Do que se ocupa efetivamente a escola atual? Qual sua função? A que se dedica?

Tais perguntas tornam-se pertinentes porque a escola tem deixado de ocupar-se do trabalho com o conhecimento escolar e passado a ocupar outras funções, como guarda, tutela e cuidado. Essa modificação na função é vivenciada por todos, alunos e professores. Há um "mal-estar", no espaço escolar, acalentado pelo descompasso entre o imaginário da função pedagógica presente na cabeça dos professores, a realidade e necessidades prementes dos alunos e a expectativa dos pais.

Tal problemática gera uma indefinição nesse espaço e em suas práticas. Essa imprecisão é alimentada pelo conjunto volumoso de reformas que tem privilegiado a escola para sua realização. 
No entanto, os estudiosos da área do Currículo que se ocupam de temas como reforma curricular há muito apontam para a necessidade de entendermos as especificidades da escola. Nesse sentido, nos parece que a despeito dessas diferençadas abordagens há sempre presente um elemento quando o objeto de estudo é a escola, qual seja, o reconhecimento da existência de uma cultura própria dessa instituição. Cultura essa que a conforma de uma maneira muito particular, com uma prática social própria e única.

Podemos dizer que existem inúmeras características que aproximam os comportamentos das escolas e há uma infinidade de outras que os diferenciam. A escola ocupa uma posição estratégica, uma identidade específica no processo escolar, portanto, é um lugar concreto de trabalho e de investimento, isto é, lugar de decisão.

A atenção ao sistema de relações que a define, controlado e atravessado por questões de poder, permite compreender o modelo burocrático de regulação - tensão estrutural permanente entre a vontade do controle racionalizador das práticas de ensino e o caráter relativamente incerto e imprevisível dos acontecimentos educativos — , bem como compreender como a escola se organiza.

As formas pelas quais as escolas recebem as exigências da política educacional, advinda dos órgãos gestores centrais, se dão de maneiras distintas. Cada escola possui um processo muito particular de lidar com o conjunto de normativas e, principalmente, de incorporar ou não essas exigências, também de distintas maneiras.

A escola é historicamente uma instituição da sociedade, com um papel razoavelmente claro: "o que define a escola (...) é precisamente o fato de ser um ambiente formativo de identidades" (SILVA, 1996, p. 47). Tendo em vista essa definição, a escola tem uma função social básica que vai além de prestar serviços educativos. Logo, não pode ser entendida como uma organização social, pois essa figura burocrática está calcada na necessidade de gerir seu espaço e tempos particulares o que, obviamente, contradiz as premissas que instituem a função social da escola e o seu entendimento como um mundo social instituído de uma cultura própria.

O modo como a escola vem se organizando tem reforçado mecanismos geradores de adaptação e de dominação. São esses mecanismos que certamente informam os processos pedagógicos organizativos, de gestão e de tomada de decisões no interior da escola, os quais vão além da legislação ou das recomendações feitas pela(s) entidade(s) mantenedora(s) da escola e/ou pelo poder público. 
Assim, a escola, principal instituição da sociedade responsável pela educação formal dos indivíduos, difere grandemente das organizações sociais. A estrutura organizacional da escola não está sustentada apenas por um plano racional determinado pela burocracia, ela é uma totalidade mais ampla "compreendendo não apenas as relações ordenadas conscientemente, mas, ainda, todas as que derivam de sua existência enquanto grupo social” (CANDIDO, 1964, p. 107).

Sendo a escola, portanto, uma instituição da sociedade, ela é base para o conceito de sociedade moderna com o qual a humanidade se identifica, ou mais, a escola é "elemento fundante" para o espírito de modernidade, "um dos principais motores de triunfo da modernidade" (PINEAU, 1999, p. 39).

O que se está buscando apontar é que:

(...) a escola constitui um ambiente social peculiar, caracterizado pelas formas de tensão e acomodação entre administradores e professores - representando os padrões cristalizados da sociedade - e os imaturos [os alunos], que deverão equacionar, na sua conduta, as exigências desta com as da sua própria sociabilidade (...).

[E que] (...) a vida interna da escola (...) reelabora, segundo a sua dinâmica interna, as normas, valores, práticas comunitárias, dando-lhes uma coloração nova, mas nem por isso alheia ao encadeamento geral da sociedade (CANDIDO, 1964, p. 111 e 128).

A organização, estrutura de funcionamento e de tomada de decisões no cotidiano escolar é peculiar, diversa do que espera e estabelece a política educacional adotada pelos órgãos gestores, mas nem por isso ela não é funcional ou eficiente ou eficaz. As escolas são instituições especiais e diferentes das organizações sociais, conforme afirma Nóvoa:

As escolas são instituições de um tipo muito particular, que não podem ser pensadas como qualquer fábrica ou oficina: a educação não tolera a simplificação do humano (...) que a cultura da racionalidade empresarial sempre transporta (NÓVOA, 1998, p. 16).

A cultura perpassa todas as ações do cotidiano escolar, seja na influência sobre os seus ritos ou sobre a sua linguagem, seja na determinação das suas formas de organização e de gestão, ou na constituição dos sistemas curriculares.

Viñao Frago (2000) lembra que a cultura escolar tem sido entendida como uma das "caixas pretas" da historiografia educacional, passando a conceituá-la como

modos de pensar e atuar que proporcionam a seus componentes estratégias e pautas para desenvolver-se tanto nas aulas como fora delas - no resto do recinto escolar e no mundo acadêmico - e integrar-se na vida cotidiana das mesmas (VIÑAO FRAGO, 2000, p. 100). 
A função da cultura escolar não seria promover uma incorporação de outros valores não os objetivos escolares, ou mesmo de servir de ferramentas para a inculcação de valores, pelo menos não são apenas essas as resultantes promovidas pela cultura escolar. Esse autor concebe a cultura escolar como aquele conjunto de práticas, normas, idéias e procedimentos que se expressam em modos de fazer e pensar o cotidiano da escola. E,

esses modos de fazer e de pensar - mentalidades, atitudes, rituais, mitos, discursos, ações amplamente compartilhados, assumidos, não postos em questão e interiorizados, servem a uns e a outros para desempenhar suas tarefas diárias, entender o mundo acadêmico-educativo e fazer frente tanto às mudanças ou reformas como às exigências de outros membros da instituição, de outros grupos e, em especial, dos reformadores, gestores e inspetores (VIÑAO FRAGO, 2000, p. 100).

Os indivíduos e suas práticas são basilares para o entendimento da cultura escolar, particularmente no que se refere à formação desses indivíduos, à sua seleção e ao desenvolvimento da sua carreira acadêmica. Assim, como os discursos, as formas de comunicação e as linguagens presentes no cotidiano escolar constituem um aspecto fundamental de sua cultura.

Observamos, então, a escola como uma instituição bastante ímpar, estruturada sobre processos, normas, valores, significados, rituais e formas de pensamento que constituem sua própria cultura, a qual não é monolítica, nem estática ou repetível.

Forquin (1993) apresenta o conceito de "Cultura Escolar" como sendo aquele conjunto de saberes, que, uma vez organizado, didatizado, compõe a base de conhecimentos sobre a qual trabalham professores e alunos. E nessa está pressuposta uma seleção prévia de elementos da cultura humana, científica ou popular, erudita ou de massas.

São esses elementos estruturais determinantes nos processos pedagógicos, organizativos, de gestão e de tomada de decisões no interior da escola, os responsáveis pela instituição daquilo que chamamos de "mundo social" da escola, ou seja, o conjunto de "características de vida próprias, seus ritmos e ritos, sua linguagem, seu imaginário, seus modos próprios de regulação e de transgressão, seu regime próprio de produção e de gestão de símbolos” (FORQUIN, 1993, p. 167).

A necessidade de conformação dos objetivos educacionais aos limites apresentados pela sociedade em cada período da história também tem impacto decisivo no estabelecimento da cultura escolar, pois é uma cultura que a cada período apresenta os limites que traçam a fronteira do possível e do impossível. 
Esse conceito ou categoria evidencia uma questão, isto é, a escola é uma instituição da sociedade que possui suas próprias formas de ação e de razão construídas no decorrer da sua história, tomando por base os confrontos e os conflitos oriundos do choque entre as determinações externas a ela e às suas tradições, o que acaba por refletir na sua organização e na sua gestão, nas suas práticas mais elementares e cotidianas, nas salas de aula e nos pátios e corredores, em todo e qualquer tempo, segmentado, fracionado ou não.

Tyacke e Tobin (1994), ao descreverem a estrutura comum presente em quase todas as escolas, denominam tais características de "gramática do ensino". Ao chamarem a atenção para a presença constante de ciclos de reforma na história atual da educação escolar, destacam: "a menos que os reformadores comecem a lidar com a 'gramática do ensino' histórico, seus esforços para dar início a uma mudança curricular serão sempre frustrados" (1994, p. 453).

Em Bourdieu e Passeron (1992), por exemplo, encontramos a afirmação de que os papéis da escola são a produção e a reprodução das condições institucionais para a reprodução cultural e para a reprodução social. Em outras palavras, a escola tem desenvolvido um padrão cultural, não apenas de repetição de comportamentos, mas de desenvolvimento mesmo de raciocínios para a solução dos diferentes problemas e para a convivência.

Como "força formadora de hábitos", a escola provê aos que têm estado submetidos direta ou indiretamente à sua influência, não tanto de esquemas de pensamento particulares ou particularizados, senão desta disposição geral, geradora de esquemas particulares suscetíveis de serem aplicados em campos diferentes de pensamento e de ação, que se pode chamar de habitus culto (BOURDIEU, 1997, p. 25).

Parece que a escola conforma os indivíduos dotando-os "de um sistema de esquemas inconscientes que constituem sua cultura” (BOURDIEU, 1997, p. 26), isto é, uma cultura fundada em uma infinidade de práticas adaptadas a situações sempre renovadas, sem nunca se constituir em princípios explícitos.

Contudo, essa mesma cultura não é simples reprodutora, tampouco refratária a mudanças, pois ela tem sua própria identidade construída entre o que escutam, o que leem, o que já sabem e acreditam ideologicamente os indivíduos. Isso posto, mesmo reconhecendo a contribuição dos estudos que demonstram o caráter reprodutor da educação, é possível ver a necessidade de associá-la às suas características produtoras. 
Assim, nem toda produção cultural é uma produção ideológica, ou pelo menos, não deve ser vista desse modo, mesmo que a generalização dos conceitos de ideologia e de cultura permita essa aproximação: “Dizer que toda prática cultural é necessidade 'ideológica' não quer dizer nada mais (...) senão que toda prática é significativa” (WILLIAMS, 1992, p. 28).

Por outro lado, nos parece que atualmente a escola sofre o que alguns chamam de excesso de mandatos (NÓVOA apud AFONSO, 2010). As diferentes políticas educacionais, em especial as de currículo têm escolhido a escola como locus privilegiado para implantar mudanças.

No entanto, nossas pesquisas têm apontado que a ênfase dessas políticas está nos aspectos organizacionais da escola sem priorizar o trabalho pedagógico de sala de aula. Entendemos que a defesa do acesso e da universalização de uma educação básica de qualidade para a maioria da população, incluindo os sujeitos que historicamente foram alijados desse processo, aparentemente ênfase das reformas educacionais, perde o foco quando não respeita a especificidade do universo escolar.

Como afirma Goodson (2008, p. 39):

\begin{abstract}
De um modo geral, o que estou querendo dizer com isso, é que a escolha do momento da mudança curricular deve ser feito cuidadosamente. Essa é uma lição primária das histórias da educação. Atualmente, essa escolha do momento para as iniciativas de mudança é extremamente problemática devido às forças globais que já consideramos. É bem possível que, nos tempos atuais, as forças progressistas devessem estar a favor da conservação educacional e não a favor da mudança.
\end{abstract}

Tal lição deve estar sempre presente quando se trata da escola. As escolas são instituições que cumprem com as tradições coletivas, que têm determinadas finalidades humanas e que são produtos de ideologias sociais e econômicas, os currículos respondem a estas determinações das escolas, já que eles respondem às necessidades de certo controle social através de formas de interação relativamente padronizadas do conhecimento transmitido, que é visto como normativo por grande parte dos educadores. 


\section{Políticas de currículos locais: observando suas construções em redes de ensino}

As políticas curriculares podem ser entendidas como uma fixação autoritária de valores, dado que constituem uma retórica operacional, com intenção prescritiva e congregam um complexo e heterogêneo conjunto de elementos cruciais para a sua compreensão. Devem, por isso, ser entendidas como um sistema e uma cultura, uma vez que não se podem cingir aos fatos isolados da administração, como a produção e regulação dos textos normativos.

\section{Toda política curricular é, assim, uma política de constituição do conhecimento escolar [...]. Ao mesmo tempo, toda política curricular é uma política cultural, pois o currículo é fruto de uma seleção da cultura e é um campo conflituoso de produção de cultura, de embate entre sujeitos, concepções de conhecimento, formas de entender e construir o mundo (LOPES, 2004, p. 3).}

Efetivamente, essas políticas contêm contradições, omissões e diferentes significados que produzirão diferentes efeitos, tendo em conta que desde o momento de sua concepção ao de sua implementação, verificam-se inúmeros filtros que determinam o percurso das intenções e acrescentam diversas leituras, uma vez que a produção de significados está dependente dos contextos em que se inserem.

Deste modo, "as dinâmicas no seio de sectores institucionais como a educação são consequências de complexas articulações de interesses que emergem da sociedade civil e da economia e que constroem, mantêm e limitam os poderes do Estado” (ROBERTSON; DALE, 2001, p. 122).

As ações da política curricular não são neutras, há uma intencionalidade em sua elaboração e ela pode ser definida de acordo com Pacheco (2005), como:

a expressão de uma legitimidade e de um poder relacionados com tomadas de decisões sobre seleção, organização e avaliação de conteúdos de aprendizagem, que são a face visível da realidade escolar, e ainda com o papel desempenhado por cada ator educativo na construção do projeto formativo do aluno (p.02).

É importante compreendermos também que as próprias políticas educacionais têm diferentes contextos de produção e implantação. Para auxiliar nessa perspectiva, temos nos utilizado também dos estudos de Stephen Ball. Ball (2001) aponta três contextos políticos primários, cada um deles com diversas arenas de ação, públicas e privadas.

O primeiro, o contexto de influência, onde as definições políticas são iniciadas e os discursos políticos são construídos, é o espaço em que acontecem as disputas entre quem influencia a definição das finalidades sociais da educação, constituindo o marco ideológico das políticas. $\mathrm{O}$ segundo, o contexto de produção dos textos das definições políticas, localizado no poder central, mantém uma associação direta com o primeiro contexto. E, por fim, o terceiro, o contexto da 
prática, refere-se ao espaço no qual as definições curriculares são recriadas e reinterpretadas. No contexto da prática, os efeitos das políticas curriculares são condicionados por questões institucionais e disciplinares (BALL, 2001) por suas diferentes histórias, concepções pedagógicas e formas de organização que produzem diferentes experiências e habilidades em responder às mudanças curriculares, reinterpretando-as.

Desse modo, temos o contexto da influência e da produção que referem-se a contextos mais globais e temos a forma como localmente cada escola participa disso e é nesse aspecto que centramos nossa análise.

Nos currículos nacionais estão presentes a ideia e a prática de conteúdos gerais válidos para toda uma nação. Diante disso, procuramos a compreensão das estratégias escolares colocadas em marcha no interior de documentos curriculares locais como indutoras, ou melhor, reforçadoras das expectativas em relação à cultura, à educação e às práticas sociais.

Aos documentos curriculares estava estabelecida a função de garantir o acesso aos conhecimentos previamente definidos nos Parâmetros Curriculares Nacionais (1998) e nos Referenciais Curriculares Nacionais de Educação Infantil (1999), que ao se apresentarem como parâmetros, indicavam que as redes de ensino deveriam construir diretrizes curriculares próprias, visando atender às especificidades de cada região e oferecer condições para uma formação cidadã e participativa.

Como expressões dessa construção, encontramos em duas redes de ensino, estadual e municipal, de um estado brasileiro, a apresentação de cinco documentos curriculares entre os anos de 2000 e 2008, a saber: Rede Municipal - Diretrizes Curriculares do Ensino Fundamental (2003), Diretrizes Curriculares para a Educação Infantil (2003) e Referencial Curricular da Rede Municipal de Ensino do $1^{\circ}$ ao $9^{\circ}$ ano (2008); Rede Estadual - Fundamentos do Currículo ou Caderno Temático da Série Constituinte Escolar (2000) e Referencial Curricular da Educação Básica (2008). Esses documentos foram apresentados por administrações ligadas ao Partido dos Trabalhadores (PT) e ao Movimento Democrático Brasileiro (PMDB) que, desde então, se alternam nos poderes.

Esses documentos, mesmo expressões de administrações com ideologias diferençadas, parecem comungar de um ideário teórico metodológico cujas leituras são desenhadas a partir de aproximações ao que identificam como "marxismo". De um lado, a luta dos partidos de esquerda pela manutenção dos ideários da educação popular (MATO GROSSO DO SUL, 2000) e de outro, a afirmativa de que a sociedade atual traz necessidades materiais e espirituais resultantes 
do modo com que se organiza e se produz. O movimento de reprodução do capital produz, simultaneamente, a miséria humana como condição da própria sobrevivência do capital (CAMPO GRANDE, 2008).

No entanto, o que parece interessar a esse suposto "marxismo" no campo curricular está determinado pelo reconhecimento das habilidades trazidas pelos alunos de sua convivência familiar, podendo colocar em desvantagem aquele aluno que não possuísse os códigos necessários para conviver neste espaço-tempo-escolar. Isso reduz a política de distribuição de conhecimentos aos mecanismos de reprodução da desigualdade. Para fazer um exame daquilo que é tido como um conhecimento oficial, parece necessário rever todo conjunto de valores, ações e crenças que se encontram fora da escola, criando uma articulação entre a ordem social e o lugar da escola neste processo de maximização da igualdade econômica, social e cultural.

Em que pesem as diferenças entre os documentos dessas redes, no que tange ao espaço e ao tempo, é possível percebermos semelhanças na interpretação e consolidação da necessidade de um documento curricular. Interpretação que se assenta na ideia de que eles, independentemente dos anos de sua produção e das condições concretas de existência do processo de escolarização e escolaridade, estruturam e refletem o conhecimento oficial que intencionalmente deve garantir uma determinada funcionalidade das escolas, uma determinada regulação social.

Os conhecimentos e as disciplinas que os estruturam e distribuem, surgem assegurados por meio de um conjunto de "instrumentos pedagógicos", entre os quais podemos destacar a noção de aluno, a relação entre esse e o professor, os objetivos, traduzindo desejos e aspirações que fundamentam seu tons ideológicos.

Seja pelo nível de detalhamento e fragmentação que alcançam, seja pela complexidade de suas formulações ou justaposição de concepções e conceitos não explícitos, os documentos curriculares locais são centralizadores, complexos e com pouca integração entre os níveis de escolarização. Diante disso, tendem a complexificar as prescrições acerca do que se deve ensinar nas escolas, incluindo não somente conteúdos temáticos, mas enfoques, aproximações, recomendações metodológicas, instrumentos e formas de avaliação e indicações sobre a formação requerida dos professores.

Por isso, compreendemos que as mudanças sugeridas por esses documentos, além de serem recontextualizadas no espaço das práticas curriculares da escola, por si só podem não conduzir para avanços significativos no processo de escolarização. Essa análise alimenta-se da ideia de que parecem servir à burocracia administrativa, ao omitir qualquer proposição ou registro 
sobre a formação inicial ou contínua dos professores que estarão em ação, bem como sobre as condições de trabalho, dos meios disponíveis para construir práticas ou mesmo das experiências e conhecimentos acumulados.

\section{NOTAS FINAIS}

Uma análise, ainda que superficial, das políticas de escola e de currículo, nos diz que elas se convertem em ordens de significação implicados na reprodução, ou não, das ideologias dominantes. Nesse sentido, parecem estar a construir a ideia do futuro como repetição, pois parece não se tratar, somente, de aperfeiçoar o estado de coisas, mas de não questioná-lo radicalmente, já que qualquer mudança supõe um retrocesso, uma volta ao passado.

Junto a isso, as retóricas da qualidade e da inovação assentam-se sobre duas lógicas. A primeira aponta a qualidade como uma propriedade e um atributo diferenciador e, portanto, universal. A segunda, como um direito somente desejável e conquistado pelos indivíduos empreendedores.

Por fim, as políticas de escola e de currículo adentraram o espaço escolar, em finais do século XX e início do XXI, com uma força que provoca alteração na cultura escolar de um modo contundente e, talvez, sem referentes na nossa história educacional. E essas alterações podem ser frutos de uma mudança de discursos pedagógicos ideologizantes ou da capacidade de solicitar outras práticas, ao mesmo tempo em que possibilitam seguir fazendo o mesmo.

\section{REFERÊNCIAS}

AFONSO, Almerindo. Discursos sobre a escola enquanto organização curricularizada. In: IX Colóquio sobre questões curriculares, V Colóquio Luso Brasileiro - Debater o currículo e seus campos políticas, fundamentos e práticas. 2010, Porto. Anais. Porto: CIIE, 2010.

BALL, Stephen, J. Diretrizes políticas globais e relações políticas locais em Educação. Currículo Sem Fronteiras, dez. 2001, v.1, n.2, pp. 99-116.

BOURDIEU, Pierre e PASSERON, Jean Claude. A reprodução: elementos para uma teoria do sistema de ensino. $3^{\text {a }}$ ed., Rio de Janeiro: Francisco Alves, 1992.

.Espacio social y espacio simbólico. Introducción a uma lectura japonesa de La distinción. In: ___ Capital cultural, escuela y espacio social. Madrid: Siglio Veintiuno Editores, 1997, p. $23-40$.

Ci. Huma. e Soc. em Rev., RJ, EDUR, v. 34, n. 12, jan / jun, p. 177-190, 2012 
BRASIL. Secretaria de Ensino Fundamental. PCNs: introdução aos Parâmetros Curriculares Nacionais. Secretaria de Educação Fundamental. Brasília, MEC/SEF, 1998.

. RCNEI: introdução aos Referenciais Curriculares para a Educação Infantil. Brasília, MEC/SEF, 1999.

CANDIDO, Antonio. A estrutura da escola. In: PEREIRA, Luiz; FORACCHI, Marialice M. Educação e Sociedade. 6. ed. São Paulo: Editora Nacional, 1971.1964

CAMPO GRANDE. Secretaria Municipal de Educação. Diretrizes Curriculares do Ensino Fundamental. Campo Grande: Prefeitura Municipal, 2003.

. Diretrizes Curriculares para a Educação Infantil. Campo Grande: Prefeitura Municipal, 2003.

. Referencial Curricular da Rede Municipal de Ensino do $1^{\circ}$ ao $9^{\circ}$ ano. Campo Grande: Prefeitura Municipal, 2008.

FORQUIN, Jean-Claude. Escola e cultura: as bases sociais e epistemológicas do conhecimento escolar. Tradução: Guacira Lopes Louro. Porto Alegre: Artes Médicas, 1993.

GIDDENS, Anthony. As Conseqüências da Modernidade. Tradução de Raul Fiker. São Paulo: UNESP, 1991.

GOODSON, Ivor. As políticas de currículo e de escolarização. Rio de janeiro: Vozes, 2008.

LOPES, Alice Casemiro. Políticas Curriculares: continuidade ou mudança de rumos? Revista Brasileira de Educação. Rio de Janeiro, ANPED, 2004, nº. 26, p. 109-118.2004

LUNARDI-MENDES, Geovana M. Nas trilhas da exclusão: as práticas curriculares no atendimento as diferenças dos alunos. 2005. 270f. Tese (Doutorado em Educação) - Pontifícia Universidade Católica de São Paulo, 2005.

MATO GROSSO DO SUL. Secretaria de Estado da Educação. Fundamentos do Currículo. Caderno Temático da Série Constituinte Escolar. Campo Grande: SED, 2000.

SED, 2007.

. Referencial Curricular da Educação Básica (Ensino Fundamental). Campo Grande: 
NÓVOA, A. As organizações escolares em análise. Lisboa: Nova Enciclopédia, 1998.

PACHECO, José Augusto. Escritos curriculares. São Paulo: Cortez, 2005.

PINEAU, Pablo. Premisas básicas de la escolarización como construcción moderna que construyó a la modernidad. Revista de Estudios del Curriculum, Barcelona/Espanha, v.

2, n. 1, p.39-61, 1999.

SAMPAIO, Maria das Mêrces Ferreira. Um gosto amargo de escola. São Paulo: Educ, 1998.

SILVA, Fabiany de Cássia Tavares. Observatório de Cultura Escolar (4): estudo das propostas curriculares locais pós Parâmetros Curriculares Nacionais e Referenciais Curriculares de Educação Infantil (1998-2008). Campo Grande: UFMS, Pró-reitoria de Pesquisa e Pósgraduação (Projeto de Pesquisa), 2008.

. Observatório de Cultura Escolar (5): estudo de documentos curriculares locais e suas implicações para construção da diferenciação/flexibilização curricular (1998-2008). Campo Grande: CNPQ (Universal 2009), PROPP, UFMS, 2009.

SILVA, Jair Militão da. A autonomia da escola pública: a re-humanização da escola. Campinas: Papirus, 1996.

TYACK, D y CUBAN, L. En busca de la utopia. Un siglo de reformas en las escuelas públicas. México: Fondo de Cultura Econômica., 2001.

VEIGA-NETO, Alfredo. Crise da Modernidade e inovações curriculares: da disciplina para o controle. In: Eliane Peres et al. (org.). Trajetórias e processos de ensinar e aprender: sujeitos, currículos e culturas. Porto Alegre: EDIPUCRS, 2008. p. 35-58.

VIÑAO FRAGO, A. Culturas escolares, reformas e innovaciones: entre la tradición y el cambio. (mimeo), 2000.

WILLIAMS, Raymond. Cultura. Rio de Janeiro: Paz e Terra, 1992.

Submetido em: 04/2012

Aprovado em: 06/2012 